$\pi_{12} / 2$

\title{
MASTER
}

UCRL-51708

\author{
J. A. Rínde \\ R. R. Stonie
}

January 9, 1975

Prepared for U.S. Atomic Energ,' Commissiónitndercontract No. W-7405-Eng-48

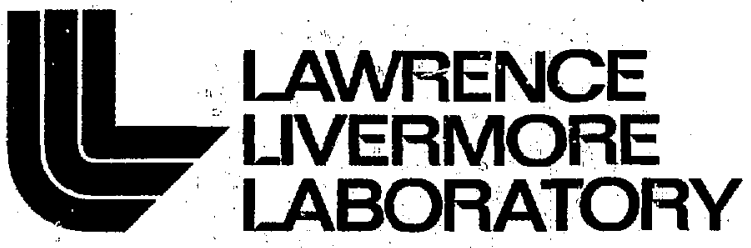

University of Calfómia / ivermore 


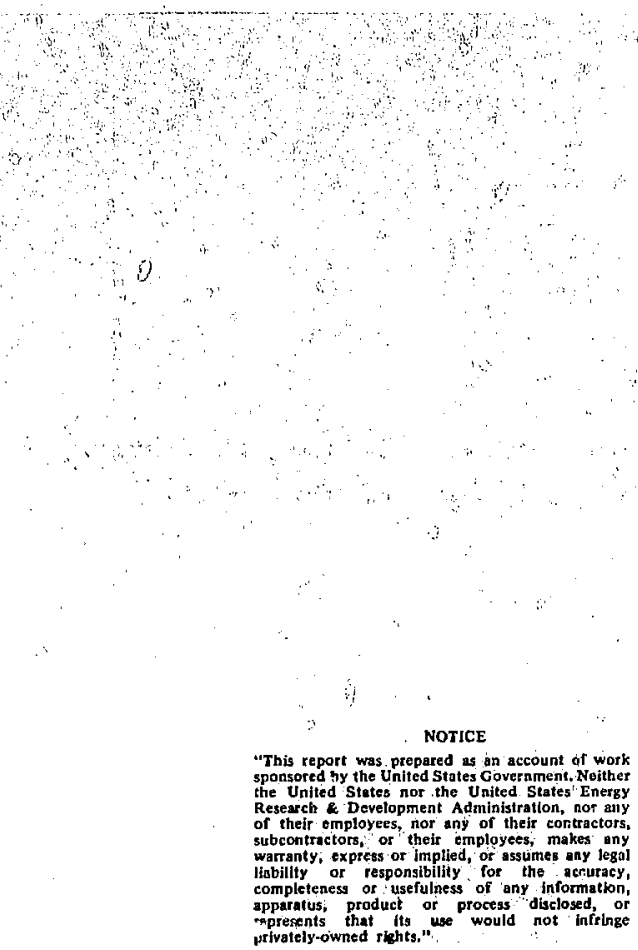

Printed in the United States of America Available from

National Technical Information Service...

U.S. Department of Commerce 5285 Pc rt Royal Road Springfiela, Virginia 22151

Price: Printed Copy $\$$; Microfiche $\$ 2.25$

NTIS

\begin{tabular}{c} 
Fages \\
\hline $1-50$ \\
$51-150$ \\
$151-325$ \\
$326-500$ \\
$501-1000$
\end{tabular}

Selling Price

$\$ 4.00$

$\$ 5.45$

$\$ 7.60$

$\$ 10.60$

$\$ 13.60$ 
TID-4500, UC-34

Physics-General

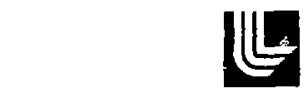

LAWRENCE LNERMOAE LABOAATOFY

Univasity of Caifome/Livermore Caffornia/94550

UCRL- 51708

\section{PREPARATION AND FABRICATION OF LOW-DENSITY \\ MICROCELLULAR-FOAM LASER TARGETS}

J. A. Rinde

R. R. Stone

MS. date: Jantary 9, 1975

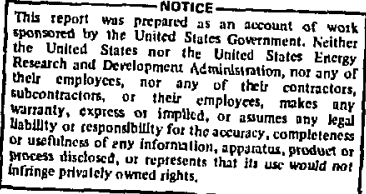




\title{
PREPARATION AND FABRICATION OF LOW-DENSITY MICROCELLULAR-FOAM LASER TARGETS
}

\begin{abstract}
We described the fabrication of lowporation of hollow glass microspheres into density microcellular foam for use in $D, T$-filled laser targets and the incorthis foam. Steps in the manufacture of the target are described.
\end{abstract}

\section{Introduction}

One version of the LLL standard $\mathrm{D}-\mathrm{T}$ filled, hollow glass microsphere laser target calls for a low-density foam layer to surround the target microsphere. In this target, the foam layer (made of cellulose acetate) must be from 10 to $30 \mu \mathrm{m}$ thìck, have a density of $0.1 \times 10^{3} \mathrm{~kg} / \mathrm{m}^{3}$, a cell size of $2 \mu \mathrm{m}$ or less, and a chemical composition of low average atomic number. In this report we describe the preparation of a foam that meets the se specifications, the incorporation of hollow glass microspheres into this foam, and steps in the manufacture of this laser target.

\section{Background}

As indicated ahove, the cellulose acetate foam needed must have a low density and very small cell size. Normal foams, such as polystyrene, polyurethane, polyethylene, etc., can be obtained in low densities between 0.01 and $0.1 \times 10^{3} \mathrm{~kg} / \mathrm{m}^{3}$; however, the cell size is generally too large, $200 \mu \mathrm{m}$ and above. Other foams produced by the same expansion techniques have similar cell sizes. To achieve small uniform cells, the number of nucleation sites must be increased so that more. smaller cells develop. One foam of this type is Yneumacel," made by du Pont. This foam has a density of $0.02 \times 10^{3}$ $\mathrm{kg} / \mathrm{m}^{3}$ and cells that are about $25 \mu \mathrm{m}$ in diameter. Foams have been reported that have cells a few micrometres in diameter; however, these all have high densities. To achieve both low density and micrometre-size cells in the same foam, we used a phase-inversion technique to proriuce our cellular atructure. This process is discussed below.

\footnotetext{
Reference to a company or product name does not imply approval or recommendation of the product by the University of California or the U.S. Atomic Energy Commission to the exclusion of others that may be suitable.
} 


\section{Method for Making Foams}

The phase-inver'sion process we used to make low-density microcellular foams was derived from methods of making asymmetric, reverse-osmosis membranes for water desalination. ${ }^{1-6}$ However, dile to the different product desired, our process and solution formulations differ substantially from those used for the membranes.

Our basic procedure for making cellulose acetate foam is to dissolve the polymer in a solvent system consisting of a good solvent, a swelling agent, and a nonsolvent. This solution is either cast on a flat plate to form a thin sheet, which is then dipped into ice water to gel the polymer, or it is extruded from a small diameter orifice directly into the ice water. The polymer gels in the ice water, which is a nonsolvent for cellulose acetate, and the solvent and swelling agent diffuse out of the polymer gel. After soaking in water, the polymer gel is freeze-dried to form the foam.

\section{Discussion of Variables Affecting Gelation Process}

In the phase-inversion process, it has been reported ${ }^{2}$ that the initially homogeneous solution separates into two interspersed liquid phases prior to the actual transition from solution to gel. These interspersed phases can be considered as consisting of droplets of one liquid phase embedded in a matrix of the other. These droplets represent the incipinnt voids in the finlshed gel and they unust be stabilized in the solution-to-gel transition. Three principal steps occur in the phase-inversion process during the extrusion of the cellulose acetate solutions into colo water;

(1) loss of solvents, (2) gelation, and (3) loss of residual solvent and swelling agent.

From the brief description of the process for making polymer gels, it is clear that the cellulose acetatr polymer system has definite requirements that must be met to achieve a polymer gel with the desired properties, Since the variables affecting this process are many and very spectific, we discuss them in terms of the particular formulation currently being used to produce foams. This formulation is:

- 6.0 g cellulose acetate, Fastman E-4655

- $10.0 \mathrm{~g}$ magnesium perchlorate, anhydrous

- $30.0 \mathrm{~g}$ water

- 15.0 g ethyl D-L lactate

- 39,0 g acetone.

The Eastman E-4655 polymer is a high viscosity polymer of about $17 \mathrm{~Pa} \cdot \mathrm{s}$, which has been substituted to $39.4 \%$ acetyl and contains $3.8 \%$ hydroxyl. This is one of several. cellulose esters that could be used, the other esters vary in viscosity from 1 to $25 \mathrm{~Pa} \cdot \mathrm{s}(10-25 \mathrm{p})$ and also in acetyl and hydroxy content. We chose the Eastman E-4655 polymer to maintais a high viscosity in our dilute solutions. The polymer concentration is a primary variable in controlling the density of the final foam. Foams from the above formulation with $6 \%$ cellulose acetate genera!ly 
have densities from 0.1 to $0.15 \times 10^{3} \mathrm{~kg} / \mathrm{m}^{3}$ depending olr other variables. Wu used formulations with as little as $4 \%$ cellulose acetate and achieved foam densities of $0.08 \times 10^{3} \mathrm{~kg} / \mathrm{m}^{3}$. The highest density foam we produced is $0.6 \times 10^{3} \mathrm{~kg} / \mathrm{m}^{3}$; but higher densities can be made.

The next two components in the solution formulation, magnesions perchlorate and water, make up the swelling agent. The exact mechanisms of these components' interactions with the polymer and each other is wot clearly understood. However, we know they are needed to make porous polymer gels. If they are not used, only full-density films can be fabricated. As the magnesium perchlorate concentration in the swelling agent increases, the amount of water incorporated into the polymer gel increases (to a limit) and thus reduces the ultimate foam jensity. This is tue to the $\mathrm{Mg}^{++}$ions, which hydrate the water present. Studies ${ }^{2}$ have shown that magnesium ions from magnesium perchlorate can have up to 80 waters of hydration aggregated about each $\mathrm{Mg}^{++}$ion. This action is demonstrated by the fact that water is a nonsolvent for cellulose acetate, while a concentrated solution of magnesiurn perchlorate in water will dissolve cellulose acetate. The magnesium ions also probably form complexes with the $\mathrm{OH}$ and $\mathrm{CO}$ groups on the cellulose acetate. ${ }^{2}$ However, our work has stews that the $\mathrm{Mg}^{+4}$ ions are not strongly boun:l to the cellulose acetate gel since soaking the polymer gel in water for $24 \mathrm{~h}$ will reduce the $\mathrm{Mg}^{++}$ion concentration to $50 \mathrm{ppm}$,

The acetone and ethyl lactate in the above formulation are solvents for cellulose acetate. They were chosen to meet requirements of the phase-inversion and extrusion processes. For phase inversion to take place and yield microcellular gels, the solvents must be misciblc with each other and soluble in water. Also, the solvents must diffuse out of the polymer gel readily into water, and any residual solvents must come out on freeze-drying without changing the size or shape of the frozen gei. This is important because in our planned procedure the amount of time that the gel can soak in water to allow the solvents to diffuse out is $24 \mathrm{~h}$ or less. This means that some residual solvent may remain in the gel and must be removed at low temperatures during the freezedrying process. Therefore, the solvents must have high vapor pressures at low temperatures.

Ethyl lactate was chosen as a solvent due to the extrusion process. During extrusion, the cellulose acetate solution is forced from a small diameter need?e, 100-450 $\mu \mathrm{m}$ diameter, the point of which is located below the surface of the water bath and is pointed down. The polymer solution will fall away from the needle as a smooth cylinder if its density is about $1.0 \times 10^{3} \mathrm{~kg} / \mathrm{m}^{3}$ or higher. The addition of ethyl lactate increases the solution density. Although a cellulose acetate solution with an all-acetone solvent would be better for the freeze-drying process because of the higher vapor pressire of acetone, this solution will not extrua * smoothly in our apparatus.

Another very important variable in achieving foams with the desired properties is the temperature of the water bath. To get foams with cell sizes in the micrometre range requires that the polymer solution be gelled in water of $10^{\circ} \mathrm{C}$ or less. Gels produced at $0^{\circ} \mathrm{C}$ are opalescent while 
gels produced from the same solution at $25^{\circ} \mathrm{C}$ are opaque. The opalescent gels have submicroscopic pore structure and are called ultragels. ${ }^{7}$ The opaque gels have pore structures that are discernible under a microscope and are called microgels. Foams produced from ultragels are preferable because they are translu- cent to light and we can see the hollow glass microspheres that are located in the atrands. Foams produced from microgels are opaque to transmitted light which makes locating the hollow glass microspheres more difficult. However, some microgels have pores in the 1- to 2- $\mu \mathrm{m}$ range and would make acceptable foams.

\section{Experimental}

\section{A PPARATUS}

Figure $I$ is a photograph of our apparatus. It consists of a hydraulic cylinder that provides the force to move a silicone rubber piston located in the vertical tube. This piston contacts the cellulose acetate solution located in the bottom section of this tube and lorces the solution containing the hollow micruspheres out of a hypodermic needle and into the water bath where gelation takes place. The water is contained in a long dewar that provides good temperature control and sufficient distance for the gelling polymer to travel and set before it encounters a solid surface. The orifices are steel hypodermic needles and special-drawn-glass capillary tubes. These glass tubes have an internal extrusion die, which we developed to locate the hollow microspheres in the center of the cellulose acetate gel. A cross section of the die is shown in Fig. 2. The raised part of the die causes the hollow microspheres to exit in the middie while the cellulose acetate solution flows and becomes cyliudrical after exiting the die.

The die was made by placing four solld gilass rods inside a hollow glass tube. The inside diameter of the tube and the diameter of the glass rods are selected according to the hollow microsphere's outside diameter and the desired outside diameter of the foam. The hollow tube with the equally

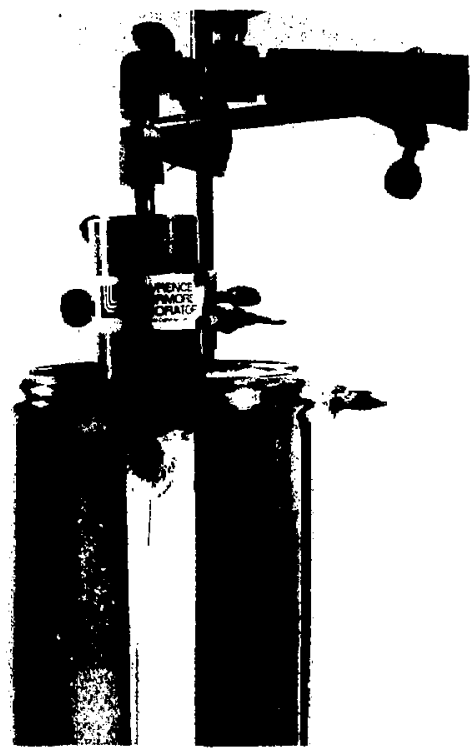

Fig. 1. Extrusion apparatus. 
spaced glass rods is heated slightly at two points about $100 \mathrm{~mm}$ apart to weld the glass rods to it. This assembly is then heated between the two weld spots and pulled down without breaking. The outside diameter is measured and the pulled down glass is broken at an outside diameter corresponding to the proper inside diarneter. The broken end is then ground flat. Finally, the die is : otted in epoxy to give it some support and is ready for use.

\section{PROCEDURE}

1 he first step in preparing these laser targets is to add D, T-filled hollow glass microspheres to a solution of cellulose acetate. Next, the solution is simultaneously gelled and shaped by forcing it out of a $100-\mu \mathrm{m}$ orifice (the same size as the desired target diameter) into ice water. This produces a long cylinder of gel that is allowed to soak in the water to extract additives. When the gel is relatively free of impurities, it is frozen in -70 to $-80^{\circ} \mathrm{C}$ liquid pentane and transferred to a freezedrying chamber. During freeze-drying, water and solvents sublime and the gel structure solidlfies into foam.

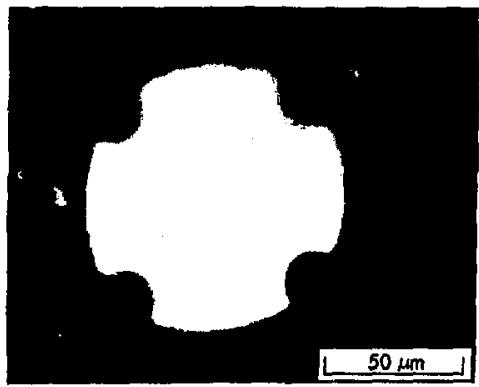

Fig. 2. Cross section of ball locator extrusion die.
Table 1 givas a chemical analysis of the cellulose acetate foam we produced and Table 2 lists the trace elements found.

Table 1. Results of chemical analysis of cellulose acetate foam produced by phase-inversion process.

\begin{tabular}{|c|c|c|}
\hline & Element & $\begin{array}{c}\text { Content } \\
(\%)\end{array}$ \\
\hline i & $\begin{array}{l}\mathrm{C} \\
\mathrm{H} \\
\mathrm{N} \\
\mathrm{O}\end{array}$ & $\begin{array}{r}47.44 \\
5.67 \\
\text { none } \\
46.89^{a}\end{array}$ \\
\hline
\end{tabular}

Table 2. Trace elements present in cellulose acetate foam as found by chemical analysis.

\begin{tabular}{cr}
\hline Element & ppn \\
\hline $\mathrm{Fe}$ & 400 \\
$\mathrm{Si}$ & 400 \\
$\mathrm{Cu}$ & 200 \\
$\mathrm{Na}$ & 200 \\
$\mathrm{Al}$ & 100 \\
$\mathrm{Mg}$ & 100 \\
$\mathrm{Ca}$ & 80 \\
$\mathrm{Cr}$ & 80 \\
$\mathrm{~Pb}$ & 80 \\
$\mathrm{Zn}$ & 80 \\
$\mathrm{~B}$ & 40 \\
$\mathrm{Ga}$ & $<40$ \\
$\mathrm{Mn}$ & 20 \\
$\mathrm{NI}$ & 20 \\
$\mathrm{Ag}$ & 10 \\
$\mathrm{Sr}$ & 6 \\
$\mathrm{Be}$ & $<2$ \\
\hline
\end{tabular}

Table 3. Hieat capacity of the cellulose acetate polymer determined by a Perkin Eimer DSC-1 scanning calorimeter.

\begin{tabular}{cc} 
Temperature & $\begin{array}{c}\text { Heat } \\
\text { capacity } \\
\left(\mathrm{J} / \mathrm{kg}-{ }^{\circ} \mathrm{K}\right)\end{array}$ \\
\hline 30 & 1.05 \\
50 & 1.17 \\
90 & 1.25 \\
110 & 1.38 \\
190 & 1.51 \\
210 & 1.76 \\
\hline
\end{tabular}


The heat capacity of the cellulose acetate polymer was determined using a Perkin Elmer DSC-1 scanning calorimeter with a sapphire standard. Table 3 gives the results.

The heat capacity was also estimated by the Kopp-Joule procedure. These results, given in Table 4, are higher than those obtained with the DSC calorimeter.
Table 4. Heat capacity of the cellulose acetate polyman estimated by tine Kopp-Joule $p_{\text {: }}$ cedure.

\begin{tabular}{cc}
\hline & $\begin{array}{c}\text { Heat } \\
\text { capacity } \\
\left(\mathrm{J} / \mathrm{kg}^{\circ} \mathrm{K}\right)\end{array}$ \\
\hline-50 & 1.21 \\
20 & 1.30 \\
80 & 1.42 \\
\hline
\end{tabular}

\section{Results}

We made several cellulose acrtate foams and in this section present photomicrographs showing hollow glass micr:ospheres incorpcrated in foam strands, the shape o. the foam strands, and tlie cell size of the foam. The figures show that the foam meets the requiremeats discussed and also that the hollow mirrospheres are well incorporated into the foam. The photomicrographs were taken using both normal optical microscopes and sra.ning eiectron microscopes (SEM).

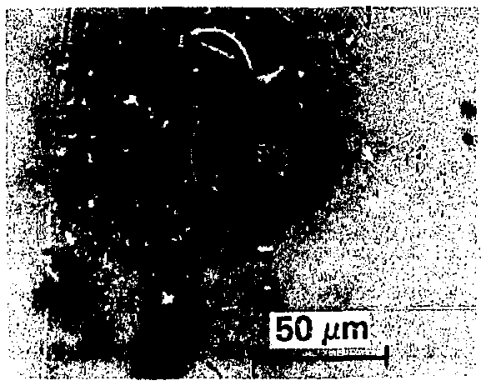

Fig. 3. Optical photomicrograph showing 55- $\mu \mathrm{m}-$ diameter hollow glass microsphere located in a $160-\mu \mathrm{m}$ diameter strand of cellulose acetate gel.
Figure 3 shows a 55-um hollow glass microsphere located in a $160-\mu \mathrm{m}$ strand of cellulose acetate polymer gel. The photo shows that the hollow microsphere is well centered in the gel strand and that the diameter of the gel strand varies by about 5\% (for the segment shown). The gel is m.stly clear and has no large air bubbles or other abnormalities near the hollow microsphere. The irregularities seen in the figure are due to surface contamination. Figure 4 shows $z$

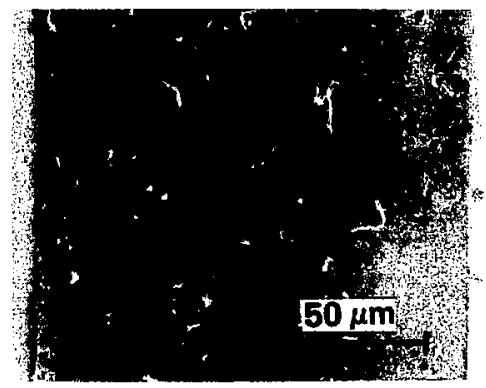

Fig. 4. Optical photomicrograph showing a 50- $\mu \mathrm{m}$-diameter hollow glass microsphere located in a 140- $\mu \mathrm{m}$-diameter cellulose acetate foam strand. 


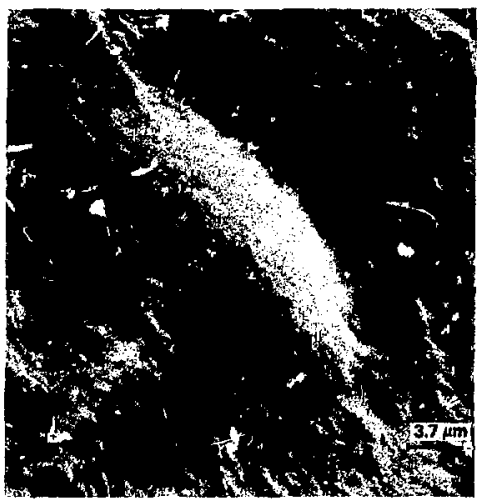

Fig. 5. Scanning electron micrograph of a cellulose acetate foam strand showing a hollow microsphere located just below the foam s'srface.

50- $\mu \mathrm{m}$-diameter hollow glass microsphere located in a celluiose acetate foam strand; that is, after freeze-drying. The hollow microsphere is centered to within $\pm 5 \mu \mathrm{m}$ out appears to have a void space surrounding it. This void space varies from 2 to $4 \mu \mathrm{m}$ in width. At this time, we do not know if this void space occurs all the time or if it can be eliminated. Both Figs. 3 and 4 were taken at $500 \times$ with transmitted light. Because of the clarity of the foam, we can see that the foam cell size is lass than $1 \mu \mathrm{m}$. This same type of result can be seen in Fig. 5, a SFIM photograph taken at $2700 \times$, which shows a fractured surface of a cellulose acetate foam strand that contains a hollow glass microsphere just below the surface. Becauso the fracture did not penetrate to the hollow microsphere surface, we can see that the hollow microsphere is $w .11$ incorporated in the foam and that at least a thin layer of

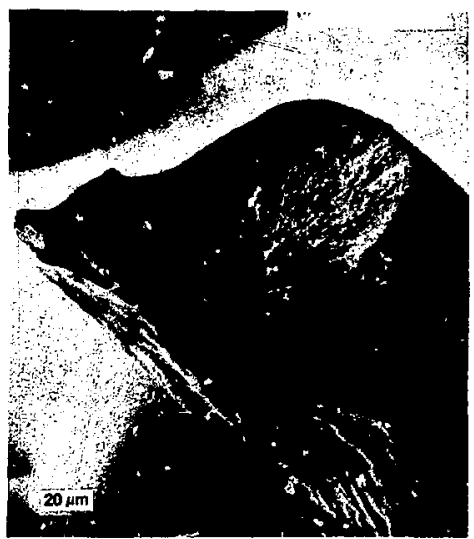

Fig. 6. SEM photograph at 500X of fractured surfacn of a foam strand.

the cellulose acetate adheres to its surface.

The biggest problem ic characterizing these foams is in determining their densities. These foams are open celled which means that the cells are interconnected and that the volume cannot be measured by fluıd displacement techniques. ive determine the density by the veightvolume method and calculate the volume from the foam dimensions. Since we extrude cylinders, we need to have a uniform, round cross section tu get a gooò volume measurement. Figure 6. a SEM photograph taken at 500 $\times$, shows a foam sirand that has been fractured in liquid nitrogen. The strand has a nearly circular cross sertiun. Since both the polymer gel and the fram are sof: materials that are easily damaged or distorted, great care rnust be taken to obtain uniform cross sections. Figure 6 shows that this 


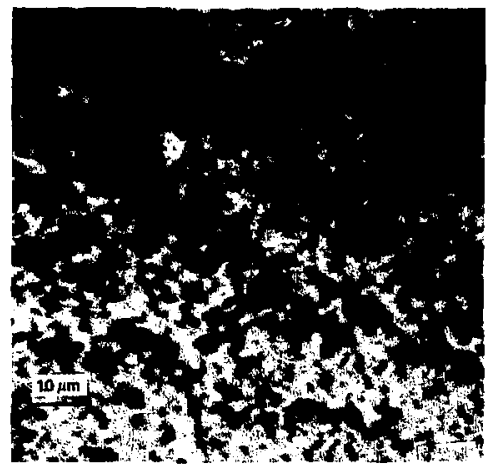

Fig. 7. SEM photograph at 10,000X of fractured surface of foam strand in Fig. 6 showing the cell size to be less than $0.3 \mu \mathrm{m}$.

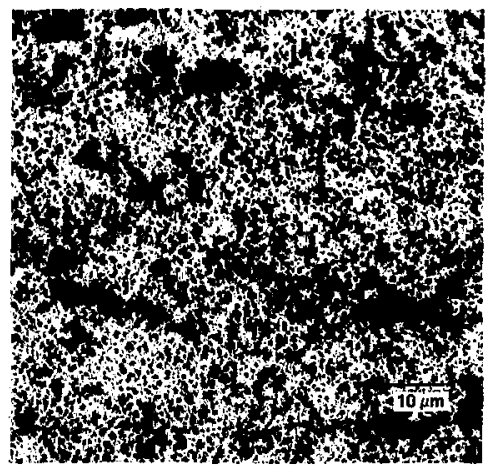

Fig. 8. SEM1 photograph ic $1000 \mathrm{X}$ of a fractured suriace of a cellulose acetate foam having a uniform cell size of 1 to $2 \mu \mathrm{m}$.

reveals that no cellular structure greater than $1 \mu \mathrm{m}$ can be seen. To see the cells in this foam we must go to higher magnifications. Figure 7 is a SEM photograph at $10,000 \times$ of a fracture surface of the foam in Fig. 6. The 1- $\mu \mathrm{m}$-long marker on Fig. 7 shows that the average cell size is les 5 than $0.3 \mu \mathrm{m}$. We have praduced foams with uniform cells in the 1 - to $2-\mu m$ range and an example is shown in Fig. 8 . As mentioned previously, this form is opaque to transmitted light.

\section{Target Fabrication}

The target to be made with cellulose acetate foam has the shape of a right circular cylinder of foam with a hollow glass microsphere located in the center. The nominal dimensions of this target are a 50- $\mu$ m-diameter hollow glass microsphere enclosed in a foam cylinder,
$100 \mu \mathrm{m}$ in diameter and $100 \mu \mathrm{m}$ long. This target is completed by bonding it to the end of a 5-um-diameter glass stalk.

To make the target, the cellulose acetate foam rod with a hollow microsphere inside is carefully pushed inside a small-diameter Teflon tube. The tube is 
pulled down until it holds the foam firmly. This foam and tube assembly is placed inside of a larger Teflon tube which ls also pulled down tight against the smaller tubing. This assembly is placed in a fixture and the hollow microsphere position is found with a microscope. The assembly is then cut the proper distance from the center of the shell. The right circular cylinder with the gas-filled shell is then separated from the tubing and is now ready for assembling with its glass holder.

The foam is cut with a razor blade vibrated on the end of a metal strip. The blade is glued across a fork which is attached to a thin metal strip. A coil is placed close to the strip and an ac current is driven through the coil. The varying magnetic field drives the strip-razor blade assembly and allows the amplitude and frequency of the vibration to be controlled. Figure 9 shows the cutting apparatus.

The right circular cylinder of foam is glued uiko a pulled glass stalk $w$ ith a tip outside diameter of about $5 \mu \mathrm{m}$. The stalks are made by heating and pulling capillary tubes down to the proper size.

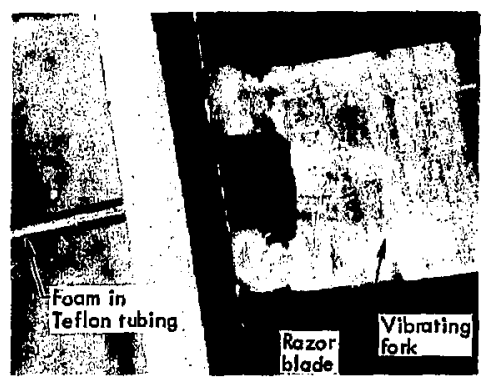

Fig. 9. Strip-razor blade assembly for foam cutting.
The assembly station consists of a highquality microscope and two micromanipulators. The foam cylinder is picked up by means of a microvacuum chuck and positioned by one of the manipulators. A two-part epoxy is mixed and then injected in the large end of the glass stalk with a syringe. This glass stalk is mounted into a hollow rod, connected to a rubber bulb. The bulb can te squeezed to pressurize the inside of the glass stalk. The end of the glass stalk is brought lip to the foam cylinder by use of a manipulator and pressure is applied against the adhesive to force it out the

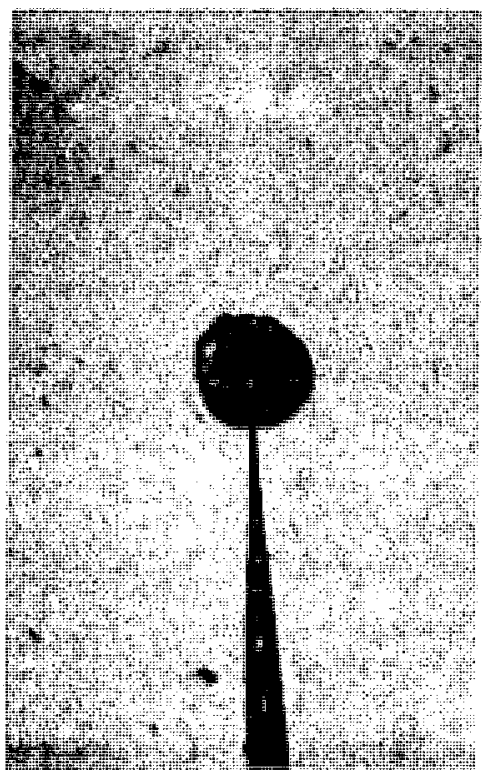

Fig. 10. Mockup of target showing hollow glass microsphere embedded in cellulose acetate foam. 
tip. The assembly is allowed to set for about $30 \mathrm{~min}$ and is then removed from the gluing station. The glass stalk with the foam target is then glued into a metal holder. The complete assembly is now ready for attaching to the position in the laser chamber. A mockup of the complete assembly is ahown in Fig. 10.

\section{Acknowledgments}

We would like to thank L. P. Althouse and N. Lee for their very fine experimental work in support of this program,
W. Steele for performing the scanning electron micrographs, and $\mathbf{E}$. Catalano for the heat capacity calculations.

\section{References}

1. S. Lueb and S. Sourirajan, Dept. of Engineering, University of California, Los Angeles, Calif., Rept, 60-60 (1961).

2. I. E. Kesting, J. Appl. Polym. Sci. 9, 663 (1965).

3. R. E. Kesting, M. K. Barsh, and A, L. Vincent, I, Appl. Polym. Sci, 9, 1873 (1965).

4. B. Kunst and S, Sourirajan, J. Appl. Polym. Sci. 14, 1983 (15-70).

5. B. Kunst and S, Sourirajan, J. Appl. Polym. Sri, 14, 723 (1970).

6. R. E. Kesting, Synthetic Polymer Memoranes (McGraw-Hill, New York, 1970\%, Ch. 5 .

7. W. Elford, Proc. Royal Soc, (London) B 106, 216 (1940). 